ANL-82-91

\title{
ANL Micrometeorological Measurements of Particle Sulfur Deposition at the 1981 Dry Deposition Intercomparison Experiment
}

by

M. L. Wesely, D. R. Cook, and R. L. Hart

Radiological and Environmental Research Division Argonne National Laboratory

Argonne, IL 60439 
ANL Micrometeorological Measurements of Particle Sulfur Deposition at the 1981 Dry Deposition Intercomparison Experiment

M. L. Wesely, D. R. Cook, and R. L. Hart

Radiological and Environmental Research Division

Argonne National Laboratory, Argonne, II 60439

\section{Introduction}

The Dry Deposition Intercomparison Experiment conducted in September; 1981, was designed by the Illinois State Water Survey as a pilot effort to evaluate various methods of measuring pollutant dry deposition. A more extensive experiment was planned for June, 1982, when additional and improved techniques were to be implemented. The 1981 study focused on sulfate aerosol, while the 1982 experiment will consider a wider range of particulate substances and some gases. At issue is whether traditional monitoring methods using surrogate surfaces to collect dry deposition can routinely provide estimates in agreement with results from applications of intensive micrometeorological techniques. This report sumarizes the micrometeorological data gathered in 1981 by Argonne National Laboratory.

\section{Measurements}

Both turbulence and mean data were collected at the Monticello Road site near Champaign, Illinois. The fast-response instrumentation for the turbulence measurements was placed at a height of $6.2 \mathrm{~m}$ above the soil surface, which was covered with grass $30-40 \mathrm{~cm}$ tall. Data were obtained at a rate of $20 \mathrm{~s}^{-1}$ and stored on digital magnetic tape while eddy-correlation statistics were computed in real time. The variables measured include vertical wind velocity with a propeller anemometer, horizontal wind speed with 
a fast-response cup anemometer, temperature with a microbead thermistor, water vapor content with a Lyman-alpha hygrometer, and particulate sulfur concentration with flame-photometric sensors. The wind, temperature and water vapor sensors have been described in previous publications (e.g., Wesely et a1., 1978). One of the sulfur sensors, a modified Meloy Model $285^{*}$ provided by the Aerosol Research Branch, Environmental Sciences Research Laboratory (ESRL), Research Triangle Park, was used as described by Hicks et al. (1982). Another Meloy Model 285*, largely unmodified, was used by ANL on Sept. 10 and 11, and an instrument designed and constructed at the University of Michigan at Ann Arbor was used on Sept. 12 and 13.

Use of the fast-response instruments allowed direct eddy-correlation measurements of the friction velocity $u_{*}$, sensible heat flux $H$, latent heat flux $L_{W} E$, and sulfur fluxes $F_{X} \cdot$ Appendix I lists the final estimates. Some notable adjustments to the data are as follows:

1. Compensation for the lags due to the time of transit of air through the tubing from the sampling point to the reaction chambers of the sulfur sensors was applied to the data when the magnetic tapes were played back for final analysis.

2. Corrections for inadequate frequency response of the sensors were computed following well-established procedures (e.g., as outlined by Wesely, 1982) that utilize values of height above the surface, mean wind speed, sensor exponential response time, and atmospheric stability.

3. Effects of interference by water vapor in the ESRL sulfur sensor were removed from flux estimates by use of information from laboratory tests and

\footnotetext{
* This does not constitute approval of this product by the research organizations involved, to the exclusion of other commercial products suitable for the same purpose.
} 
the evaluations of water vapor fluxes in the field. These corrections are large and at times seem to overcompensate, which caused the fluxes to appear sma1l and even directed upwards occasionally, especially in data collected during mornings. Some of these upward fluxes have been deleted from Appendix I and were ignored in the analyses described later. Laboratory tests of the other sulfur sensors indicate that corrections for the effects of water vapor interferences were not necessary.

4. Adjustments of the sulfur fluxes were made as given by Webb et al. (1980) and Wesely et a1. (1981), to account for the effect of mean Stefan flow associated with evaporation at the surface and the effects of correlation between density variations and vertical wind fluctuations. Typically, these adjustments caused a reduction of the downward fluxes by about $10 \%$.

The mean data listed in Appendix I are from other instruments. Given are averages of wind speed $\mathrm{u}$ for a height of $6.2 \mathrm{~m}$ above the soil surface, wind direction at a height of $9.7 \mathrm{~m}$, the mean differences $\Delta \mathrm{T}$ of air temperature between heights of 7.0 and $0.5 \mathrm{~m}$, mean air temperature $T_{a}$ at $1.0 \mathrm{~m}$, water vapor pressure e at $0.7 \mathrm{~m}$, and net radiation $\mathrm{R}_{\mathrm{n}}$ above a representative portion of the surface.

Mean values of sulfur concentration $\chi$ shown in Table 1 are for a height of about $6.2 \mathrm{~m}$ and are derived from "streaker" data provided by the Illinois State Water Survey. Concentrations at two heights, 7.0 and $0.5 \mathrm{~m}$ were obtained; to derive estimates for $6.2 \mathrm{~m}, 0.96$ times the upper level concentration plus 0.04 times the lower value was computed, as is consistent with a logarithmetic profile. In addition, the concentrations obtained from one filter sample, located at the lower level from the beginning of the experiment until 1000 hrs CDT on Sept. 8 and then at the upper level until 1200 hrs on Sept. 11, was increased by $35 \%$. This adjustment seems necessary 
to "balance" the upper and the lower filter values for the pair of filters employed until Sept. 11; data from this particular filter were chosen for adjustment because of difficulties reported by the laboratory performing the analysis.

\section{Parameterization of Sulfur Fluxes}

Figures 1 and 2 summarize some of the data. The sulfur fluxes are those obtained with the two sulfur sensors provided by ANL (one via the University of Michigan). On Sept. 11 (Fig. 1), values of $F_{X}$ evince a strong diurnal trend, but a diurnal variation is less evident for Sept. 13 (Fig. 2), possibly because of fewer data. There is a suspiciously high correlation evident between $F_{X}$ and $L_{W} E$ on Sept. 11, which suggests an interference due to water vapor fluctuations in the Meloy instrument. However, laboratory tests indicate that the interference should have been negligible. This points to the difficulty of sorting out the factors that control sulfur deposition rates, because many fluxes are similar on a diurnal and even an hourly basis even though the mechanisms that control exchange very near and at the surface can be quite different. Determination of the factors that control sulfur deposition requires a statistical analysis, preferably applied to data collected over a wide range of conditions.

Two possibilities for parameterization of the sulfur deposition rates are given here. For both attempts, deposition velocities $v_{d}$ (downward flux divided by concentration at a height of $6.2 \mathrm{~m}$ ) are first modified by subtracting the effects of the resistance of the atmospheric layer above the aerodynamic surface roughness length, $z_{0} \approx 2.4 \mathrm{~cm}$, found for this experiment by conventional analysis of wind speeds, atmospheric stability, and values of $u_{*}$. This produces a transfer velocity $v_{t}$, invariably larger than the 
deposition velocity, which is then normalized by division by $u_{*}$. This normalization is needed because of the usual premise that $v_{t}$ is strongly dependent on $u_{*}$, plus the need to produce, a dimensionless variable $\left(v_{t} / u_{*}\right)$. The removal of the effects of aerodynamic/resistance should help make the results more universal because the variability of micrometeorological conditions above the surface can be taken into account.

Table 1. Means and standard errors of normalized transfer velocities for unstable and stable atmospheric conditions.

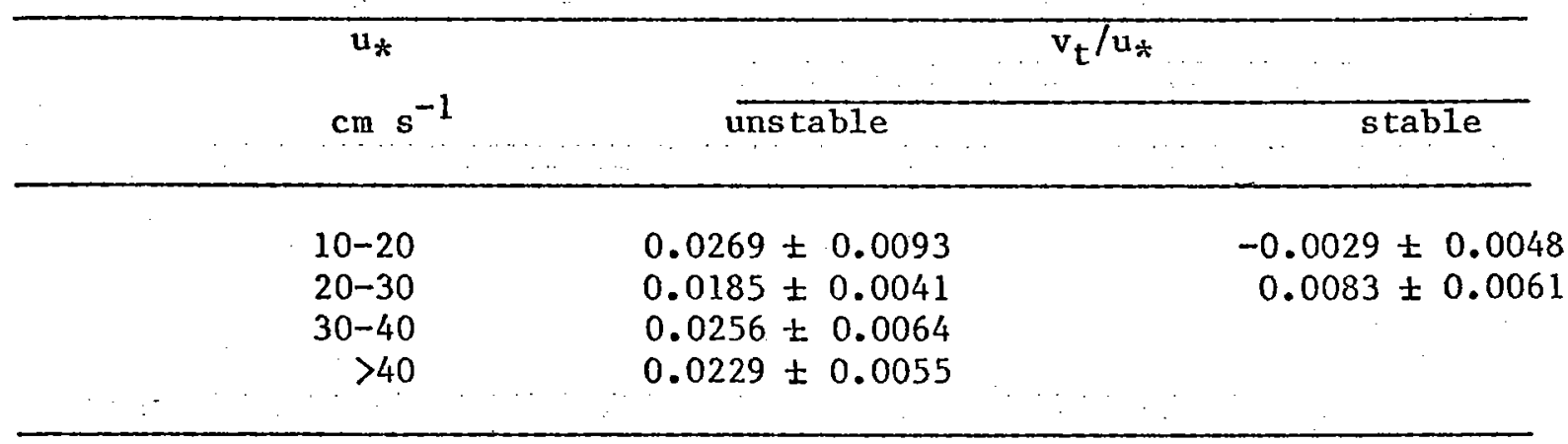

Table 1 shows the average value of $v_{t} / u_{*}$ obtained for different ranges of $u_{\%}$. Since inspection of unaveraged data reveals obvious changes of $v_{t} / u_{\%}$ with atmospheric stability (as can be seen to a limited extent in Fig. 1), the results in Table 1 are segregated into stable and unstable conditions. The dependency on atmospheric stability suggests that further analysis based on stability is warranted and Fig. 3 shows the second, more thorough attempt at parameterization in this regard. Values in Fig. 3 are grouped according to values of the well-known Obukhov length scale $L$; $\mathrm{L}^{-1}$ instead of $\mathrm{L}$ is used because of the desire to follow the usual procedure of plotting dimensionless micrometeorological turbulence variables versus $z / L$, where $z$ is the height above the surface. In this case, it is not clear what, if any, length scale should be used in place of $z$, so none is used. The surface roughness $z_{0}$ might be employed, but this is not necessarily a good measure of all the surface 
geometry characteristics that might affect impaction and interception of particles at the surface.

The results in Fig. 3, which are computed with sulfur fluxes from all the sulfur sensors employed, indicate that $\mathrm{v}_{\mathrm{t}} / \mathrm{u}_{*}$ decreases with greater $\mathrm{L}^{-1}$ when $\mathrm{L}^{-1}$ is positive and is large when $-\mathrm{L}^{-1}$ is large. In between, there is a disturbing large-value set of $v_{t} / u_{*}$ near $L^{-1}=-0.01$. This exists for data derived individually from both the ESRL sensor and from the ANL sulfur sensors. Another disturbing tendency is the accurrence of negative values of $v_{t} / u_{*}$ in very stable conditions, which would indicate an upward sulfur flux in some nighttime conditions. This was found earlier for total sulfur flux above a pine forest (Hicks et al., 1982). Overall, the data in Fig. 3 seems quite noisy, due at least in part to the small signal-to-noise ratio of the electronic signals produced by the sulfur sensors. On the average, this noise should not bias the results, but does produce a considerable amount of variability from one half hour to the next.

It seems that the best choice for parameterization at present is to assume some changes of $v_{t} / u_{*}$ with atmospheric stability, but not to consider the details of Fig. 3 very closely. Accordingly, it is recommended that we tentatively assume that $v_{t} / u_{*}$ is equal to values found for broad ranges of $L$, namely, 0.0375 for $0>\mathrm{L}\rangle-15,0.0193$ for $\mathrm{L}\langle-15,0.0077$ for $\mathrm{L}\rangle 30$, and 0.0 for $0<\mathrm{L}<30$. The accuracies of these ratios might be considerably less than implied by three significant digits.

\section{Daily Averages of Sulfur Fluxes}

Since sulfur fluxes were not measured continuously by eddy-correlation throughout the experiment, the eddy-correlation estimates cannot be used directly to compute daily averages of sulfur flux. Rather, the 
parameterization expressed above will be used. Estimates of L are determined from measurements of $\bar{u}, \Delta T$, and the value $z_{0}=2.4 \mathrm{~cm}$ found for the site. Estimating $u_{*}$ and $H$ are necessary intermediate steps, both to compute $v_{t}$ and to estimate the aerodynamic resistances used to derive the deposition velocity after $v_{t}$ is found. Figure 4 shows the relationship found between $z / L$ and the a bulk Richardson number $R_{b}$ computed as $g \Delta T /\left(\theta_{u}\right)$, where $g$ is the acceleration due to gravity and $\theta$ is the potential temperature. The theoretical relationship is given by the solid line and the dashed line is fit by eye to the data and represents the parameterization to be used here. The effects of water vapor gradients on $\mathrm{R}_{b}$ is not taken into account but the effects of water vapor flux is included in the computations of $L$. This is probably the main cause of the shift of the dashed line above the solid line where $z / L$ is near zero in Fig. 4 .

Appendix II shows the estimates of sulfur fluxes and deposition velocities at a height of $6.2 \mathrm{~m}$ for the present experiment. Data are given as 2-hr averages centered at the time indicated; corresponding to the time intervals of the original streaker data on sulfur concentrations. Table 2 shows the daily averages for the ten days with complete data in Appendix II. The average deposition velocities, computed as the daily average fIux divided by the mean daily sulfur concentration, varies from 0.14 to $0.39 \mathrm{~cm} \mathrm{~s}^{-1}$ and has a mean value of $0.27 \mathrm{~cm} \mathrm{~s}^{-1}$ for all ten days. On Sept. 11, the day with the most complete eddy-correlation estimates of sulfur fluxes, the deposition velocity is $0.24 \mathrm{~cm} \mathrm{~s}^{-1}$. This is in rough agreement with the direct eddycorrelation estimates when appropriate values for missing data are assumed, as should be the case since the parameterizations used were derived from the eddy-correlation estimates. 
Table 2. Daily average values of particulate sulfur fluxes given in Appendix II, from 0100 to $0100 \mathrm{hrs}$. Deposition velocities are derived from these averages and the listed daily mean sulfur concentrations at a height of $6.2 \mathrm{~m}$.

\begin{tabular}{|c|c|c|c|c|}
\hline \multicolumn{2}{|c|}{ day } & \multirow{2}{*}{$\begin{array}{c}\mathrm{F}_{\mathrm{x}} \\
\mathrm{ng} \mathrm{m}^{-2} \min ^{-1}\end{array}$} & \multirow{2}{*}{$\frac{x}{n g m^{-3}}$} & \multirow{2}{*}{$\mathrm{cm} \mathrm{s}^{-1}$} \\
\hline Sept. & Julian & & & \\
\hline 6 & 253 & -500 & 4000 & 0.21 \\
\hline 7 & 254 & -1240 & 5330 & 0.39 \\
\hline 8 & 255 & -210 & 1450 & 0.24 \\
\hline 9 & 256 & -110 & 1370 & 0.14 \\
\hline 10 & 257 & -770 & 3620 & 0.36 \\
\hline 11 & 258 & -620 & 4410 & 0.24 \\
\hline 12 & 259 & -610 & 5310 & 0.19 \\
\hline 13 & 260 & -800 & 5160 & 0.26 \\
\hline 15 & 262 & -640 & 3130 & 0.34 . \\
\hline 16 & 263 & -370 & 1890 & 0.32 \\
\hline
\end{tabular}

\section{Conclusions}

Eddy-correlation measurements of sulfur fluxes were measured on several days of the 1981 Dry Deposition Intercomparison Experiment but were not continuous enough to provide daily averages for all days. Based on micrometeorological variables, a tentative parameterization of the fluxes and deposition velocity is applied to yield an averge daily deposition velocity of $0.27 \mathrm{~cm} \mathrm{~s}^{-1}$. This is somewhat less than values of 0.4 to $0.5 \mathrm{~cm} \mathrm{~s}^{-1}$ that can be constructed from information from a much more preliminary parameterization suggested by Sheih et al. (1979) for summertime conditions in the eastern half of the United States, but is still considerably larger than the value of 0.1 $\mathrm{cm} \mathrm{s}^{-1}$ often assumed in numerical modeling of long range transport and deposition. It should be remembered that this experiment provides no information on deposition velocities for surfaces other than grass. Deposition velocities over other types of surfaces, particularly those much stoother such as bare soil or much rougher such as forest, might be quite different. Hence, any comparisons between these results and those derived 
from surrogate surfaces should not be extended readily to other surfaces; also, these results might not be representative of the fields of soybeans and maize that surrounded the experimental site. Perhaps the only conclusion for other surfaces that might not be challenged immediately is that the sulfur fluxes are quite small in very stable atmospheric conditions.

$\underline{\text { References }}$

Hicks, B. B., M. L. Wesely, J. L. Durham and M. A. Brown, 1982: Some direct measurements of atmospheric sulfur fluxes over a pine plantation. Atmospheric Environment, 16 (in press).

Sheih, C. M., M. L. Wesely and B. B. Hicks, 1979: Estimated dry deposition velocities of sulfur over the eastern United States and surrounding regions. Atmospheric Environment, 13, 1361-1368.

Webb, E. K., G. I. Pearman and R. Leuning, 1980: Correction of flux measurements for density effects due to heat and vapor transfer. Quart. J. Roy. Meteor. Soc., 106, 85-100.

Wesely, M. L., J. A. Eastman, D. R. Cook and B. B. Hicks, 1978: Daytime variations of ozone eddy fluxes to maize. Boundary-Layer Meteorol., 15 , 361-373.

Wesely, M. L., D. R. Cook and R. M. Williams, 1981: Field measurements of sma1l ozone fluxes to snow, wet bare soil, and lake water. BoundaryLayer Meteorol., 20, 459-471. 
Wesely, M. L., 1982: Turbulent transport of ozone to surfaces common in the eastern half of the United States. Advan. Environ. Sci. Technol.s 12, S. E. Schwartz, Ed., Wiley, New York (in press). 
FIGURE CAPTIONS

Fig. 1. Particle fluxes measured one day with the ANL Meloy sensor over grass, plotted along with friction velocity, latent heat flux, and particulate sulfur concentration at a height of $6 \mathrm{~m}$, all expressed as half-hour averages.

Fig. 2. As in Fig. 1, for another day. The values of sulfur flux, all from the University of Michigan instrument, have been smoothed for this plot.

Fig. 3. Normalized surface transfer velocities for particulate sulfur averaged for ranges of $\mathrm{L}^{-1}$. Error bars indicate standard errors.

Fig. 4. Measurements and parameterization of a bulk Richardson number versus atmospheric stability and compared to the theoretical relationship (solid line). Error bars indicate standard errors. 
Half-hour averages of fluxes and atmospheric variables measured at the September, $1981_{-3}$ experiment. Sulfur fluxes are expressed in units of $\mathrm{ng} \mathrm{m}^{-2}$ $\mathrm{s}^{-1}, x$ in $\mathrm{ng} \mathrm{m} \mathrm{m}^{-3}, \mathrm{u}_{*}$ in $\mathrm{cm} \mathrm{s}^{-1}, \mathrm{H}, \mathrm{L}_{\mathrm{W}} \mathrm{E}$ and $\mathrm{R}_{\mathrm{n}}$ in $\mathrm{W} \mathrm{m}^{-2}, \Delta \mathrm{T}$ and $\mathrm{T}_{\mathrm{a}}$ in $\mathrm{C}$, $u$ in $m$ $\mathrm{s}^{-1}$, $d$ in $\mathrm{deg}$, and $\mathrm{e}$ in $\mathrm{mb}$.

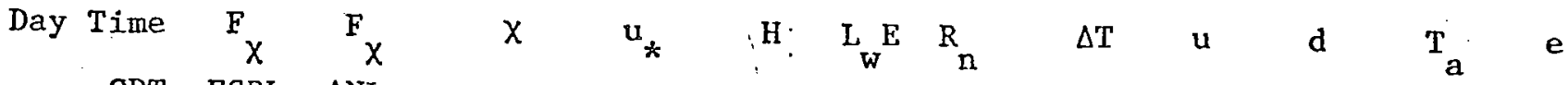
CDT ESRL ANL

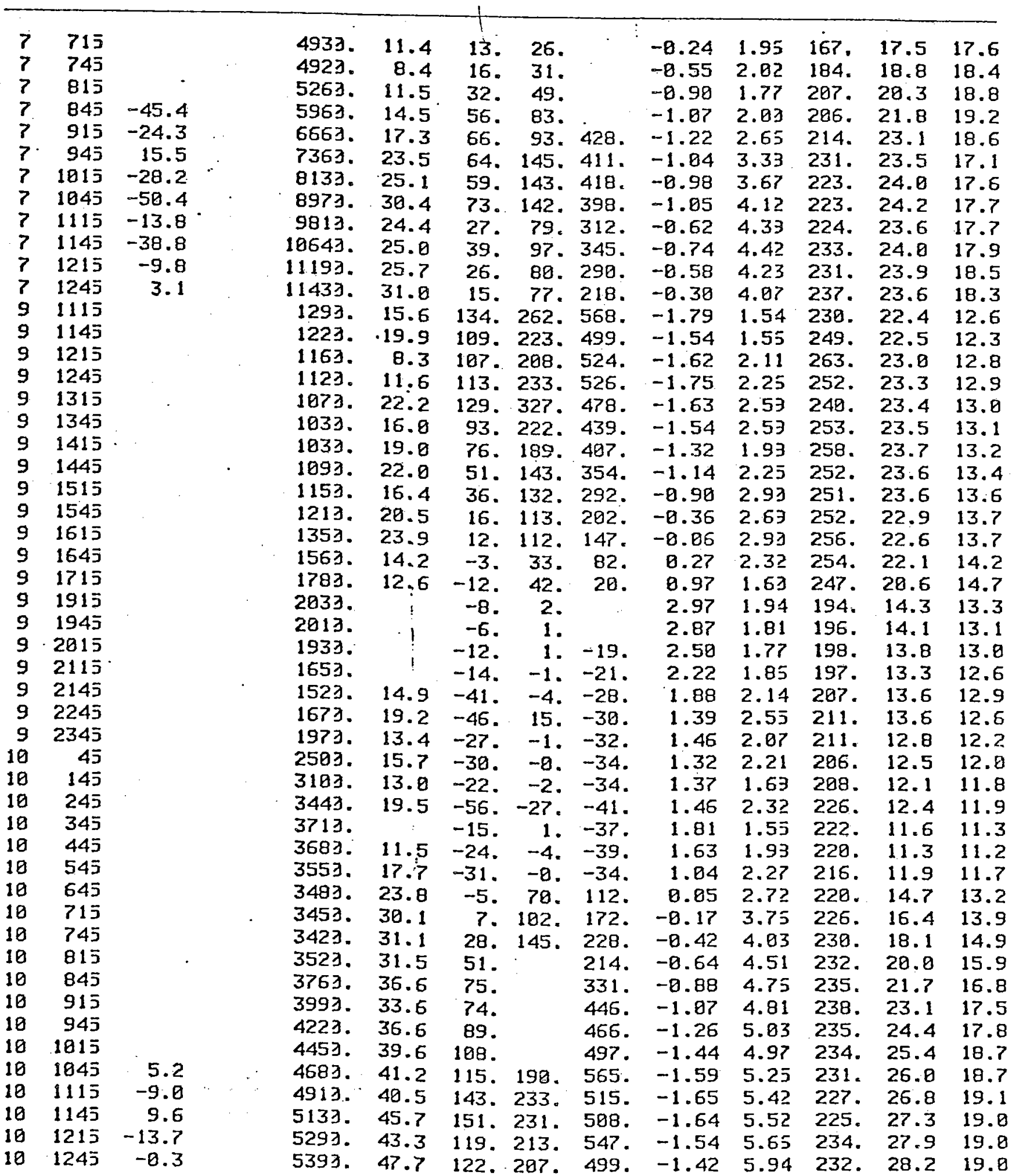




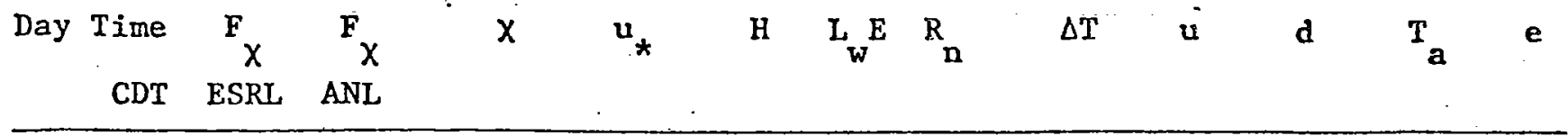

\begin{tabular}{|c|c|c|c|c|c|c|c|c|c|c|c|c|c|}
\hline $\begin{array}{l}8 \\
8\end{array}$ & $\begin{array}{l}1315 \\
1345\end{array}$ & $\begin{array}{l}-63.5 \\
-64.0\end{array}$ & & $\begin{array}{l}5483 . \\
5583 .\end{array}$ & $\begin{array}{l}45.8 \\
45.7\end{array}$ & $\begin{array}{r}135 . \\
67 .\end{array}$ & $\begin{array}{l}199 . \\
292 .\end{array}$ & $\begin{array}{l}496 . \\
455 .\end{array}$ & $\begin{array}{l}-1.30 \\
-1.12\end{array}$ & $\begin{array}{l}5.81 \\
6.23\end{array}$ & $\begin{array}{l}233 . \\
231 .\end{array}$ & $\begin{array}{l}28.7 \\
28.6\end{array}$ & $\begin{array}{l}18.8 \\
18.5\end{array}$ \\
\hline & 1415 & -77.7 & & 5503. & 49.1 & 53. & 186. & 409. & -0.92 & 5.83 & & 28.7 & 18.5 \\
\hline & & -47.9 & -24.3 & 53. & 43.1 & 3. & 154. & 51. & -0.67 & & & & 18.3: \\
\hline & 1515 & 53.7 & -69.6 & & 43.5 & 17. & 7. & 289. & -8.41 & & & & 9.2 \\
\hline & & -37.3 & -36.6 & & 38.5 & 4. & 115. & 221. & & & & & 3.4 \\
\hline & & -0.4 & 6.3 & & 29.2 & $-B$. & 79 & 147. & 0.13 & .27 & & .5 & 8.5 \\
\hline & & -0.3 & -23.2 & & 30.8 & -23 & 83. & 78. & 0.48 & .73 & 34. & & 8.31 \\
\hline & & 8.5 & -6.4 & & 21.7 & -28 & 60. & 25. & 0.98 & & 27. & & 8.7: \\
\hline & & 24.3 & -3.5 & & 13.1 & -19 & 22. & -19 & & .23 & 1. & & .6 \\
\hline & & 19.0 & -1.9 & & & -18 & 14. & -11 & & 2.23 & & 9.4 & 3.3 \\
\hline & & -11.7 & -1.3 & & & -17 & -17 & -35 & 1.76 & 2.37 & 11. & 9.3 & 8.3 \\
\hline & & -1.2 & 14.3 & & 5.4 & -19 & $-\theta$. & -41. & & .33 & & & 9.7 \\
\hline & 21 & -0.9 & -1.6 & & 10.6 & -8 & -2 & -26 & & 93 & & & \\
\hline & & -8.2 & -1.0 & & & -2 & -7. & -34 & & .75 & & .6 & .1 \\
\hline & & -0.6 & -4.9 & & & -4 & -5 & 27 & 1.23 & .83 & & .8 & .4 \\
\hline & 41 & & -0.5 & & 14.6 & -7 & & & 0.87 & 2.23 & & 5.5 & .1 \\
\hline & 61 & & -1.2 & & 14.3 & -2 & & & 24 & & & .8 & .2 \\
\hline & 62 & & -19.8 & & 17.6 & & & & & & & .9 & .7 \\
\hline & 71 & & & & 19.2 & & & & $-\theta$. & 2.21 & & .9 & .7 \\
\hline & & & -17.4 & & 29.2 & 22 & & & -8. & 2.85 & & .7 & .9 \\
\hline & & - & -15 & & 26.2 & 29 & & & & 7 & & & .4 \\
\hline & & & -15 & & 22.0 & 36. & & & & 2.5 & & 2.1 & .9 \\
\hline & 91 & & & & 15.7 & 51. & 125. & & -1 & 2.44 & & 3.5 & \\
\hline & & & & & 17.4 & 57. & 199. & & -1.33 & 2. & & .3 & \\
\hline & & & & & 24.1 & 87 . & 290. & & & & & & \\
\hline & 10 & & -40.8 & & 20.7 & & 237. & & & & & & \\
\hline & & 11.8 & & & 26.1 & 115. & 332. & & -1 & .13 & & 8.1 & .3 \\
\hline & & 4.2 & -40.2 & & 32.4 & 24. & 228 & & -8 & & & .0 & .2 \\
\hline & & 7.4 & -41.6 & & 29.2 & 15 & 223. & & 44 & 13 & & & \\
\hline & & -17.4 & -30.9 & & 26.6 & & 18 & & & & & & 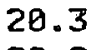 \\
\hline & & -31.5 & -29.5 & & 26.8 & & & & $-0.4 i$ & .8 & & .1 & 3. \\
\hline & & -69.5 & & & 35.2 & 52. & & & -1.84 & .3 & & 3.1 & 3.8 \\
\hline & & -5.4 & -23.7 & & 29.0 & 12. & 118. & & & & & .6 & .7 \\
\hline & & -26.1 & -41.5 & & 31.3 & & & & & & & 7.5 & 7 \\
\hline & & -16.2 & -34.4 & & 29.4 & -1 & 14 & & & & & 5.9 & 1 \\
\hline & & 5.8 & -36.8 & & 34.3 & 18. & 138 & & -0.3 & & & & \\
\hline & & 2.2 & -20.0 & & 29.4 & -5 & 9 & & & & & 3.9 & 3.9 \\
\hline & & -0.0 & -15.8 & & 22.2 & -8 & 67 & & & & & 25.6 & 0.1 \\
\hline & & 23.0 & -7.7 & & 27.7 & & 5 & & 8.8 & & & 24.2 & 9. \\
\hline & & 11.2 & & & 18.6 & -27 & $2<$ & & 1. & & & 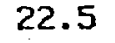 & .8 \\
\hline & & 12.3 & 5.8 & & 11.4 & -17 & & & & & & & .4 \\
\hline & & -0.8 & 2 & & 13.9 & -17. & -11 & & & & & 19.4 & 3.2 \\
\hline & & 4.4 & -1 & & & & & & & & & 18. & 7. \\
\hline & & -1.9 & -1 & & & -2 & -3. & & & & & & 7.8 \\
\hline 11 & & -6.1 & -0. & & & -5 & -13 & & & & & & 7.4 \\
\hline 11 & & 2. & 10. & & & -2 & 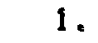 & & & & & 7.6 & 7.2 \\
\hline 1 & & -3 & 1. & & & -3 & -10. & & & & & 7. & 7.1 \\
\hline 11 & 2343 & 0.3 & 3. & & & -2 & -2 & & & & & & 17.0 \\
\hline 12 & 713 & & & & 7.5 & & 39. & & -8 & & & & 18.5 \\
\hline 12 & 743 & & & & 14.2 & & & & & & & 20.4 & 9.5 \\
\hline & 81 & & & & 15.3 & & & & & & & & \\
\hline 12 & 84 & & & & 9.2 & & & & & & & & 21.1 \\
\hline & 1. & 29 & & & & & a. & & & 1.01 & & 25.1 & $\cdots$ \\
\hline
\end{tabular}




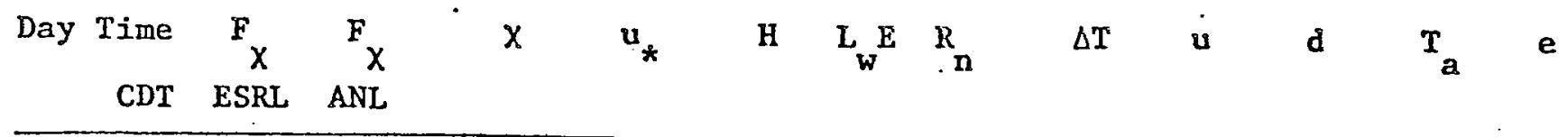

\begin{tabular}{|c|c|c|c|c|c|c|c|c|c|c|c|c|c|}
\hline & & & & & & & & & & & - & & \\
\hline 12 & 945 & 21.8 & & 5143. & & 39. & 151. & 427. & -1.10 & 1.23 & 217. & 26.4 & 21.4 \\
\hline 12 & 1015 & -10.4 & & 5183. & & 38. & 131. & 482. & -1.45 & 1.17 & 201. & 27.4 & 21.4 \\
\hline 12 & 1045 & -1.2 & & 5353. & & 53. & 204. & 494. & -1.79 & 2.83 & 184. & 28.2 & 22.0 \\
\hline 12 & 1115 & 0.7 & & 5533. & 20.8 & 59. & 220. & 585. & -1.80 & 2.72 & 193. & 28.9 & 22.2 \\
\hline 12 & $114 \overline{5}$ & 20.3 & & 5703. & 25.1 & 71. & 217. & 510. & -1.84 & 3.13 & 201. & 29.3 & 22.2 \\
\hline 12 & 1215 & -61.7 & & 5813. & 28.9 & 87. & 247 & 505. & -1.76 & 2.72 & 200. & 29.8 & 22.8 \\
\hline 12 & $124 \bar{J}$ & -22.3 & & 5863. & 16.2 & 59. & 192. & 466. & -1.64 & 3.15 & 207. & 29.9 & 22.5 \\
\hline 12 & 1315 & -12.6 & & 5913. & 21.5 & 18. & '143. & 296. & -0.62 & 3.21 & 222. & 29.8 & 21.9 \\
\hline 12 & 1345 & 2.3 & & 5963. & 21.7 & 8. & 150. & 236. & -0.30 & 2.95 & 223. & 28.8 & 22.0 \\
\hline 12 & 1413 & -25.5 & & 5883. & 21.1 & 19. & 151. & 305. & -0.51 & 2.93 & 232. & 29.2 & 22.2 \\
\hline 12 & $144 \overline{5}$ & -41.5 & & 5683. & 22.2 & 21. & 147. & 303. & -0.70 & 2.95 & 232. & 29.5 & 22.4 \\
\hline 12 & 1515 & -20.6 & & 5473. & 24.1 & 10. & 144: & 251. & -0.44 & 3.22 & 229. & 29.3 & 22.1 \\
\hline 12 & 1545 & -13.6 & 0.9 & 5273. & 15.8 & $\theta$. & 93. & 175. & -0.11 & 2.03 & 225 & 28.7 & .22 .4 \\
\hline 12 & 1615 & -3.0 & -8.4 & 5163. & 14.6 & -7 & 62. & 90. & 0.42 & 1.53 & 220 & 27.6 & 23.0 \\
\hline 12 & 1645 & 3.8 & -14.6 & 5133. & 13.1 & -10. & 46. & 55. & 0.69 & 1.67 & 216. & 27.1 & 22.7 \\
\hline 12 & 1715 & 15.8 & -0.9 & 5113. & & -7 & 20. & 23 & 1.21 & 1.43 & 203. & 26.0 & 22.6 \\
\hline 12 & 2045 & 6.0 & 1.7 & 5073. & & -2 & 1. & -21. & 1.75 & 1.95 & 175. & 20.9 & 20.7 \\
\hline 12 & 2115 & 4.6 & 1.1 & 4983. & & -1 & 1. & -23 & 1.59 & $1.8 \overline{5}$ & 176. & 20.4 & 20.1 \\
\hline 12 & 2145 & 0.4 & & 4883. & & -2 & -2 & -25 & 1.42 & 1.85 & 178. & 20.1 & 20.0 \\
\hline 12 & 2245 & 2.3 & & 4703. & & -1 & -2 & -23 & 1.40 & 1.74 & 184. & 19.6 & 19.5 \\
\hline 13 & $64 \overline{5}$ & 4.3 & & 4703. & 11.8 & 5. & 14. & 78 & 0.09 & $1.6 \geq$ & 184. & 18.5 & 19.3 \\
\hline 13 & 715 & & & 4993. & 15.0 & 9. & -22 & 136 & -0.12 & 1.47 & 193. & 19.8 & 20.8 \\
\hline 13 & 745 & & & 5283. & 7.9 & 6. & 32. & 136. & -0.37 & 1.63 & 181. & 21.2 & 21.9 \\
\hline 13 & 815 & & & 5433. & 12.0 & 23. & & 250. & -1.80 & 1.53 & 190. & 22.9 & 22.2 \\
\hline 13 & $84 \overline{5}$ & & & 5433. & 17.7 & 36. & & 283. & -1.10 & 1.33 & 207. & 24.3 & 22.9 \\
\hline 13 & 915 & & & 5443. & 14.8 & 41. & 127. & 375. & -1.42 & 1.63 & 182. & 26.8 & 24.5 \\
\hline 13 & 945 & & -7.9 & 5443. & 18.6 & 66. & 153. & 391. & -1.55 & 2.87 & 199. & 27.4 & 25.0 \\
\hline 13 & 1815 & & -13.5 & 5473. & 16.6 & 80. & 177. & 414. & -1.59 & 2.45 & 190. & 28.2 & 25.4 \\
\hline 13 & 1045 & & -21.2 & 5533. & 14.8 & 76. & 153. & 453. & -1.76 & 2.93 & 195. & 29.1 & 25.7 \\
\hline 13 & $111 \overline{5}$ & & -32.2 & 5603. & 29.0 & 102. & 199. & 471. & -1.74 & 3.47 & 193. & 29.4 & 25.5 \\
\hline 13 & 1145 & & 1.5 & 5663. & 22.3 & 52. & 124. & 347. & -1.11 & 3.23 & 200 & 29.2 & 25.1 \\
\hline 13 & 1215 & & 16.8 & 5633. & 27.8 & 51. & 134. & 393. & -1.22 & 3.82 & 197. & 29.5 & 25.4 \\
\hline 13 & 1245 & 35.7 & -31.6 & 5513. & 36.8 & 97. & 204. & 436. & -1.35 & 4.31 & 284. & 30.0 & 24.9 \\
\hline 13 & 1315 & 25.3 & -56.9 & 5393. & 27.0 & 9. & 120. & 283. & -0.55 & 3.64 & 206. & 29.2 & 24.8 \\
\hline 13 & 1345 & -29.3 & -7.0 & 5263. & 25.1 & 35. & 145. & 328. & -0.81 & 4.14 & $20 ?$. & 29.7 & 23.7 \\
\hline 13 & 1415 & -43.2 & -49.7 & 5113. & 37.9 & 48. & 155. & 333. & -0.78 & 4.64 & 282. & 29.7 & 23.6 \\
\hline 13 & 1445 & -32.4 & -16.2 & 4923. & 32.4 & -4 & 119 & 197. & -0.11 & 4.25 & 204. & 28.9 & 23.2 \\
\hline 13 & 1515 & -68.2 & -37.3 & 4743. & 36.6 & 34. & $146:$ & 273 & -0.49 & $4.5 \bar{j}$ & 202. & 29.1 & 23.8 \\
\hline 13 & 1545 & 9.3 & -32.0 & 455]. & 26.4 & -33 & 83. & 97. & 0.38 & 4.03 & 207. & 27.9 & 23.8 \\
\hline 13 & 1615 & 3.6 & 12.8 & 4413. & 29.3 & -3 & 97. & 142. & 0.08 & 3.63 & 209. & 27.8 & 23.7 \\
\hline 13 & 1645 & & -23.8 & 4313. & 22.7 & -25. & & 78. & 0.28 & 2.23 & 211. & 27.4 & 23.6 \\
\hline 13 & 1715 & & & 4213. & $19: 3$ & -40 & & 25. & 0.62 & 1.65 & 211. & 26.4 & 23.6 \\
\hline 13 & 2045 & & & 5353. & & -10 & & -32 & 0.98 & 1.03 & 283. & 20.9 & 21.2 \\
\hline 13 & 2115 & & & 5553. & 15.8 & -26 & & -34 & 0.96 & 1.32 & 201. & 20.8 & 21.0 \\
\hline 13 & 2145 & & 9.0 & 5743. & & -12 & & -32 & 1.09 & 1.83 & 209. & 20.3 & 20.4 \\
\hline 13 & 2215 & & 2.6 & 5813. & & -3 & & -26 & 1.07 & 2.07 & 210. & 19.8 & 20.0 \\
\hline 13 & 2345 & & 7.2 & 5613. & & -3 & & -14. & 0.67 & $1.7 \geq$ & 201. & 19.9 & 20.4 \\
\hline 14 & 15 & & -1.0 & 5463. & & -2 & & -12 & 0.65 & 1.63 & 195. & 19.9 & 20.4 \\
\hline 14 & 115 & & & 5023. & & -4 & & -41 & 0.68 & 1.77 & 202. & 19.8 & 20.3 \\
\hline 14 & $14 \overline{5}$ & & & 4793. & & -1 & & -28 & 0.68 & 1.71 & 285. & 20.1 & 20.7 \\
\hline 14 & 215 & & & $462 J$. & & -2 & & -120 & 0.69 & 1.65 & 210. & 20.0 & 20.5 \\
\hline 14 & 715 & & & 4373. & 8.2 & 7. & & -7 & -0.15 & 1.63 & 204. & 20.6 & 21.9 \\
\hline
\end{tabular}


Averages of fluxes and particulate sulfur deposition velocities computed from the mean variables listed and parameterizations explained in the text. ${ }^{\text {Time }}$
is hour CDT centered on 2-hr periods, $F$ is expressed in units of $\mathrm{ng} \mathrm{m}^{-1}$ $x$ in $n g \mathrm{~m}^{-3}, v_{d}$ and $u_{*}$ in $\mathrm{cm} \mathrm{s}^{-1}$, $H$ in $\mathrm{m}^{-2}, u$ in $\mathrm{m}^{-1}$, and $R_{b}$ is dimensionless.

\begin{tabular}{|c|c|c|c|c|c|c|c|c|c|}
\hline Date & Time & $\mathrm{F}_{\mathrm{X}}$ & $x$ & $\mathbf{v}_{d}$ & $\mathbf{u}_{*}$ & $\mathrm{H}$ & $\Delta \mathrm{T}$ & $\mathbf{u}$ & $\mathrm{R}_{\mathrm{b}}$ \\
\hline 5 & 18 & -0.9 & 4320 . & 0.02 & 14.5 & -19 & 8.73 & 2.21 & 0.030 \\
\hline 5 & $2 \theta$ & -0.6 & 3870. & 0.02 & 11.8 & -27 & 1.41 & 2.24 & 0.856 \\
\hline 5 & 22 & -0.7 & $41 \mathrm{j} 0$. & 0.02 & 12.7 & -16 & 0.72 & 2.33 & 0.835 \\
\hline 6 & $\theta$ & $-0 . \bar{r}$ & 4539. & 8.02 & 10.9 & -14. & 0.71 & 1.35 & 0.841 \\
\hline 6 & 2 & -0.4 & 4450. & 8.81 & 7.2 & -9 & 1.80 & 1.50 & B. 078 \\
\hline 6 & 4 & -0.3 & 3740. & 0.01 & 6.5 & -8 & 1.18 & 1.56 & 0.090 \\
\hline 6 & 6 & -8.0 & 3250. & 0.25 & 14.5 & -3 & 0.12 & $1 . \exists 1$ & 0.007 \\
\hline 6 & 8 & -9.4 & 2850 & 8.33 & 19.3 & 18. & -0.43 & 2.38 & -0.015 \\
\hline 6 & 10 & -15.7 & 3828 . & 0.41 & 24.2 & 61. & -1.11 & 2.32 & -8.826 \\
\hline 6 & 12 & -15.9 & 4428 & 0.36 & 21.2 & 69. & -1.33 & 2.47 & -0.043 \\
\hline 6 & 14 & -13.6 & 4950. & 0.27 & 16.2 & 28. & -0.72 & 1.70 & -0.040 \\
\hline 6 & 16 & -12.4 & 5210. & 0.24 & 14.1 & 19 & -0.55 & 1.55 & -0.040 \\
\hline 6 & 18 & -0.2 & 4710 & 0.00 & 3.4 & B. & $1.8 ?$ & 1.36 & 8.201 \\
\hline 6 & 20 & -0.1 & 4220. & 8.80 & 1.4 & B: & 3.75 & 1.21 & 0.510 \\
\hline 6 & 22 & -0.0 & $33 \geq 0$. & 0.00 & 0.5 & $\theta$. & 4.85 & 8.36 & 1.098 \\
\hline 7 & 8 & -0.0 & $29 \geq 0$. & 0.00 & $0 . \theta$ & $\theta$. & 2.66 & 0.31 & 5.509 \\
\hline 7 & 2 & -0.1 & 3320 . & 8.88 & 2.8 & -1 & 0.68 & 0.33 & 0.156 \\
\hline 7 & 4 & -0.1 & 3918. & 8.00 & 2.8 & D. & 1.80 & 1.34 & 0.184 \\
\hline 7 & 6 & -0.2 & 4250. & 0.01 & 4.1 & -2 & 0. 46 & 0.39 & 0.093 \\
\hline$?$ & 8 & -13.3 & 4220. & 0.32 & 18.7 & 29. & -0.69 & 2.24 & -0.827 \\
\hline 7 & 10 & -36.8 & 6630. & 0.54 & 32.1 & 74. & -1.87 & 3.77 & -0.014 \\
\hline 7 & 12 & -62.3 & 9510 & 0.65 & 38.6 & 44. & -0.56 & 4.70 & -0.805 \\
\hline 7 & 14 & -47.7 & 10350 & 0.46 & 27.2 & -4 & 0.07 & 3.51 & 0.001 \\
\hline 7 & 16 & $-48 . ?$ & $96 \geq 0$ & 0.51 & 29.8 & -4 & 0.87 & 3.35 & 0.001 \\
\hline 7 & 18 & -27.2 & 5420. & 0.50 & 29.6 & $\theta$. & 0.80 & 3.31 & 0.800 \\
\hline 7 & 20 & -25.3 & 4620. & 0.55 & 32.2 & -5 & 0.08 & 4.16 & 0.081 \\
\hline 7 & 22 & -4.7 & 1050. & 0.44 & 26.2 . & -12 & 0.24 & 3.42 & 0.004 \\
\hline 8 & 0 & -2.9 & 1030. & 0.28 & 16.3 & -10. & 0.34 & 2.21 & 0.014 \\
\hline 8 & 2 & -3.0 & 1030. & 0.28 & 16.5 & -12 & 0.38 & 2.24 & B.815 \\
\hline 8 & 4 & -3.3 & 1840. & 0.32 & 18.6 & -12 & 8.33 & 2.49 & 0.811 \\
\hline 8 & 6 & -4.9 & 1310. & 0.38 & 22.2 & $-Z$ & 0.15 & 2.39 & 0.004 \\
\hline 8 & 8 & -6.8 & 1340 . & 0.51 & 29.8 & 26. & -0.42 & 3.77 & -0.806 \\
\hline 8 & 10 & -8.8 & 1350. & 0.65 & 38.2 & 85. & -1.06 & 4.78 & -0.809 \\
\hline 8 & 12 & -7.1 & 1010. & 0.70 & 41.0 & 102. & -1.19 & 5.14 & $-B .889$ \\
\hline 8 & 14 & -4.6 & 630. & 0.67 & 39.5 & 79. & -0.96 & 4.36 & -0.008 \\
\hline 8 & 16 & -7.8 & 1350. & 0.57 & 33.8 & 14. & -0.21 & 4.32 & -0.082 \\
\hline 8 & 18 & -0.3 & 1939. & 0.01 & 9.7 & -21 & 1.51 & 2.36 & 0.071 \\
\hline 8 & 20 & -0.1 & 2130. & 0.01 & 5.1 & $\theta$. & 2.80 & 1.31 & 0.170 \\
\hline 8 & 22 & $-\theta .1$ & 2170. & 8.01 & 3.7 & 0. & 2.49 & 1.54 & 0.209 \\
\hline 9 & $\theta$ & -0.1 & 1910. & 0.00 & 3.3 & 8. & 2.95 & 1.54 & 0.248 \\
\hline 9 & 2 & -0.1 & 1750. & 0.01 & 4.9 & $\theta$. & 2.52 & 1.72 & 0.170 \\
\hline 9 & 4 & -0.1 & 1530. & 0.00 & 2.4 & B. & 3.04 & 1.37 & 0.322 \\
\hline 9 & 6 & -0.8 & 1230. & 0.00 & 1.5 & B. & 2.88 & 1.31 & 0.486 \\
\hline 9 & 8 & -1.8 & 1230. & 0.15 & 8.9 & 7. & -0.31 & 1.32 & -0.859 \\
\hline 9 & 10 & -2.3 & 1250. & 0.18 & 10.8 & 38. & -0.97 & 1.15 & -0.146 \\
\hline 9 & 12 & -3.5 & 1010. & 0.34 & 20.2 & 90. & -1.67 & 2.29 & -0.063 \\
\hline 9 & 14 & -3.3 & 859. & 0.39 & 22.8 & 77. & -1.41 & 2.58 & -0.039 \\
\hline 9 & 16 & -4.3 & 1070. & 0.41 & 24.0 & 13. & -8.26 & 3.33 & -0.806 \\
\hline 9 & 18 & -0.2 & 1810. & 0.01 & 7.6 & -12 & 2.99 & 2.19 & 0.124 \\
\hline 9 & 28 & -0.3 & 1710. & 0.01 & 10.9 & -35 & 2.73 & 2.53 & 0.885 \\
\hline 9 & 22 & -8.3 & 1240. & 0.02 & 16.7 & -52 & 1.75 & 2.76 & 0.043 \\
\hline 10 & $\theta$ & -0.4 & 1750. & 0.82 & 17.9 & -45 & 1.39 & 2.34 & 0.034 \\
\hline 10 & 2 & -0.6 & 2730. & 0.02 & 14.7 & -37 & 1.42 & 2.54 & 0.044 \\
\hline
\end{tabular}




\begin{tabular}{|c|c|c|c|c|c|c|c|c|c|}
\hline Date & Time & $F_{\chi}$ & $x$ & $\mathrm{v}_{\mathrm{d}}$ & $u_{*}$ & $\mathrm{H}$ & $\Delta \mathrm{T}$ & $\mathbf{u}$ & $R_{b}$ \\
\hline 10 & 4 & -0.6 & 3249. & 0.02 & 12.4 & -34 & 1.73 & 2.41 & 8.859 \\
\hline 10 & 6 & -10.9 & 3930. & 0.36 & 21.3 & -27 & 0.69 & 2.31 & 0.016 \\
\hline 18 & 8 & -17.9 & 2930. & 0.61 & 36.1 & 39. & -0.53 & 4.57 & -0.005 \\
\hline 10 & 10 & -27.9 & 3730. & 0.75 & 44.9 & 124. & -1.34 & 5.52 & -0.009 \\
\hline 10 & 12 & -38.5 & 4518. & 0.85 & 50.3 & 164. & -1.56 & 6.32 & -0.808 \\
\hline 10 & 14 & -43.7 & 4840. & 0.90 & 53.3 & 109. & -1.00 & 6.76 & -0.804 \\
\hline 10 & 16 & -27.6 & 3970. & 0.69 & 49.9 & -1 & 0.01 & 5.26 & 0.008 \\
\hline 10 & 18 & -0.7 & 3130. & 0.02 & 17.2 & -58 & 1.93 & 2.37 & 0.044 \\
\hline 10 & 20 & -1.0 & 3570. & 0.03 & 19.8 & -54 & 1.51 & 3.38 & 0.032 \\
\hline 10 & 22 & -0.7 & 4220 & 0.02 & 12.8 & -34 & 1.63 & 2.42 & 0.055 \\
\hline 11 & 0 & -0.8 & 4430 & 0.02 & 12.6 & -36 & 1.80 & 2.46 & 0.859 \\
\hline 11 & 2 & -0.7 & 4958. & 0.02 & 12.1 & -30 & 1.52 & 2.31 & 0.857 \\
\hline 11 & 4 & -0.8 & 3780. & 0.02 & 15.1 & -33 & 1.21 & 2.56 & 8.839 \\
\hline 11 & 6 & -0.8 & 3658. & 0.02 & 15.7 & -17. & 0.68 & 2.25 & 0.024 \\
\hline 11 & 8 & -14.3 & 3370. & 0.42 & 25.8 & 28 & -0.52 & 3.12 & -0.011 \\
\hline 11 & 18 & -14.4 & 3430. & 0.41 & 24.2 & 83. & -1.44 & 2.37 & -8.035 \\
\hline 11 & 12 & -22.0 & 4030. & 0.54 & 31.8 & 62. & -0.92 & 3.95 & -0.812 \\
\hline 11 & 14 & -31.4 & 4930. & 0.63 & 37.2 & 45. & -0.59 & 4.71 & -8.085 \\
\hline 11 & 16 & -33.6 & 5870. & 0.57 & 33.8 & 3. & -0.05 & 4.34 & -0.001 \\
\hline 11 & 18 & -1.6 & 5640 . & 0.03 & 21.1 & -55 & 1.44 & 3.18 & 0.028 \\
\hline$i i$ & 20 & -0.9 & 5140. & 0.02 & 13.2 & -39 . & 1.82 & 2.53 & 0.057 \\
\hline 11 & 22 & -0.6 & $44 \geq 8$ & 8.81 & 9.9 & -22 & 1.51 & 2.38 & 0.069 \\
\hline 12 & 0 & -0.5 & 4410. & 0.01 & 9.0 & -19 & 1.87 & 2.39 & 0.085 \\
\hline 12 & 2 & -0.4 & 4750 & 0.01 & 6.7 & -7 & 2.88 & 1.37 & 0.118 \\
\hline 12 & 4 & -0.2 & 4478 . & 0.00 & 2.8 & 0. & 1.76 & 1.24 & 0.228 \\
\hline 12 & 6 & -0.2 & 5020. & 0.00 & 3.4 & -2 & 0.92 & 1.11 & 0.149 \\
\hline 12 & 8 & -12.7 & 5780. & 0.22 & 13.0 & 16. & -0.51 & 1.52 & -0.044 \\
\hline 12 & 10 & -13.9 & 5340. & 0.26 & 15.4 & 63. & -1.36 & 1.59 & -0.095 \\
\hline 12 & 12 & -28.4 & 6830. & 0.47 & 27.6 & 114. & -1.76 & 3.28 & -0.833 \\
\hline 12 & 14 & -28.3 & 6230. & 0.45 & 26.5 & 30. & -0.53 & 3.32 & -0.010 \\
\hline 12 & 16 & -18.4 & $54 \geq 0$ & 0.34 & 20.0 & -6. & 0.14 & 2.51 & 0.004 \\
\hline 12 & 18 & -0.6 & 5330. & 0.01 & 7.8 & -11 & 2.72 & 2.16 & 0.116 \\
\hline 12 & 20 & -0.6 & 5470. & 0.01 & 8.3 & -13 & 2.46 & 2.16 & 0.185 \\
\hline 12 & 22 & -0.9 & 5070. & 0.02 & 13.6 & -34 & 1.48 & 2.45 & 0.049 \\
\hline 13 & 0 & -0.5 & 4730. & 0.01 & 7.9 & -13 & 1.85 & 1.36 & 0.896 \\
\hline 13 & 2 & -0.4 & 4330. & 0.01 & 6.1 & -5 & 1.72 & 1.70 & 0.118 \\
\hline 13 & 4 & -0.2 & 4830 . & 0.01 & 4.1 & 0. & 1.94 & 1.49 & 0.176 \\
\hline 13 & 6 & -0.4 & 4430. & 0.01 & 7.1 & -10. & 1.07 & 1.52 & 0.081 \\
\hline 13 & 8 & -15.2 & 5670 . & 0.27 & 15.8 & 25 . & -0.65 & 1.36 & -0.037 \\
\hline 13 & 16 & -22.6 & 5710. & 0.38 & 22.7 & 89. & -1.58 & 2.54 & -0.845 \\
\hline 13 & 12 & -33.7 & 5970. & 0.56 & 33.3 & 38. & -1.36 & 4.18 & -8.816 \\
\hline 13 & 14 & -34.9 & $5450:$ & 0.64 & 37.7 & 43. & -0.56 & 4.78 & -0.085 \\
\hline 13 & 16 & -28.1 & 4639. & 0.60 & 35.5 & -3 & 0.04 & 4.57 & 0.000 \\
\hline 13 & 18 & -0.9 & 4250. & 0.02 & 14.8 & -36 & 1.37 & 2.53 & 0.043 \\
\hline 13 & 20 & -0.8 & 5310. & 0.02 & 11.6 & -29. & 1.56 & 2.28 & 0.068 \\
\hline 13 & 22 & -1.2 & 6130. & 0.82 & 13.8 & -26 & 1.07 & 2.31 & 0.840 \\
\hline 14 & $\theta$ & -0.8 & 5850. & 0.01 & 10.2 & -15 & 8.84 & 1.34 & 0.849 \\
\hline 14 & 2 & -0.7 & 4910. & 0.82 & 11.0 & -14 & 0.72 & 1.36 & 0.041 \\
\hline 14 & 4 & -0.1 & 4430. & 0.00 & 2.0 & $\theta$. & 2.04 & 1.13 & 0.318 \\
\hline 14 & 6 & -0.1 & 4430 & 8.00 & 1.6 & a. & 1.28 & 0.38 & 0.388 \\
\hline 14 & 8 & -14.2 & 4730. & 0.30 & 17.8 & 1. & -0.02 & 2.29 & -0.001 \\
\hline 14 & 22 & -8.5 & 2210. & 0.39 & 22.7 & -27. & 0.62 & 3.37 & 0.013 \\
\hline 15 & 0 & -7.9 & 2330. & 0.33 & 19.5 & -18 & 0.58 & 2.54 & 0.014 \\
\hline 15 & 2 & -9.4 & $23 \geqslant 0$. & 0.41 & 24.1 & -13 & 0.28 & 3.16 & 0.086 \\
\hline
\end{tabular}




\begin{tabular}{|c|c|c|c|c|c|c|c|c|c|}
\hline Date & Time & $F_{X}$ & $x$ & $\mathbf{v}_{\mathbf{d}}$ & $u_{*}$ & $\mathrm{H}$ & $\Delta \mathrm{T}$ & $\mathbf{u}$ & $R_{b}$ \\
\hline $\begin{array}{l}15 \\
15 \\
15 \\
15 \\
15 \\
15 \\
15 \\
15 \\
15 \\
15 \\
16 \\
16 \\
16 \\
16 \\
16 \\
16 \\
16 \\
16 \\
16 \\
16 \\
16 \\
16 \\
17 \\
17 \\
17 \\
17 \\
17 \\
17 \\
17\end{array}$ & $\begin{array}{r}4 \\
6 \\
8 \\
10 \\
12 \\
14 \\
16 \\
18 \\
20 \\
22 \\
0 \\
2 \\
4 \\
6 \\
8 \\
10 \\
12 \\
14 \\
16 \\
18 \\
20 \\
22 \\
6 \\
2 \\
4 \\
6 \\
8 \\
10 \\
12\end{array}$ & $\begin{array}{r}-8.3 \\
-8.1 \\
-10.5 \\
-17.0 \\
-17.0 \\
-22.2 \\
-16.6 \\
-0.7 \\
-0.5 \\
-0.5 \\
-0.2 \\
-0.4 \\
-6.9 \\
-5.6 \\
-5.9 \\
-4.8 \\
-15.2 \\
-20.4 \\
-0.7 \\
-6.6 \\
-0.2 \\
-0.2 \\
-2.2 \\
-0.1 \\
-0.1 \\
-2.6 \\
-6.1 \\
-7.6 \\
-6.3\end{array}$ & $\begin{array}{r}2250 . \\
2250 . \\
2510 . \\
3750 . \\
4150 . \\
4150 . \\
3430 . \\
4530 . \\
3430 . \\
2570 . \\
2120 . \\
1830 . \\
2240 . \\
1910 . \\
1430 . \\
930 . \\
3330 . \\
4050 . \\
1570 . \\
1430 . \\
1330 . \\
1430 . \\
830 . \\
430 . \\
430 . \\
940 . \\
1630 . \\
2120 . \\
1430 .\end{array}$ & $\begin{array}{l}0.37 \\
0.36 \\
0.42 \\
0.45 \\
0.41 \\
0.53 \\
0.48 \\
0.02 \\
0.02 \\
0.02 \\
0.01 \\
0.02 \\
0.39 \\
0.29 . \\
0.41 \\
0.48 \\
0.45 \\
0.50 \\
0.55 \\
0.44 \\
0.01 \\
0.02 \\
0.25 \\
0.02 \\
0.02 \\
0.28 \\
0.38 \\
0.36 \\
0.42\end{array}$ & $\begin{array}{r}21.7 \\
21.1 \\
24.7 \\
26.7 \\
24.8 \\
31.5 \\
28.4 \\
11.8 \\
11.5 \\
14.6 \\
5.3 \\
14.8 \\
18.0 \\
17.4 \\
24.2 \\
28.6 \\
26.9 \\
29.5 \\
32.7 \\
26.0 \\
8.3 \\
11.9 \\
15.0 \\
13.6 \\
14.0 \\
16.5 \\
22.5 \\
21.1 \\
24.9\end{array}$ & 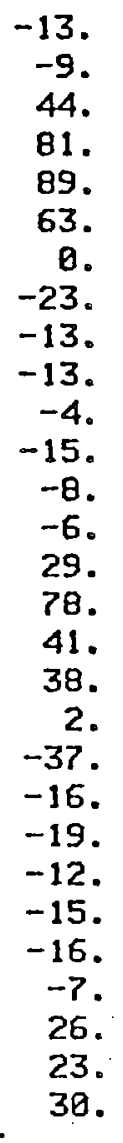 & $\begin{array}{r}0.32 \\
0.21 \\
-0.82 \\
-1.33 \\
-1.54 \\
-0.94 \\
0.80 \\
1.29 \\
0.64 \\
0.50 \\
1.33 \\
0.50 \\
0.23 \\
0.19 \\
-0.56 \\
-1.23 \\
-0.72 \\
-0.62 \\
-0.03 \\
0.74 \\
1.68 \\
0.90 \\
0.43 \\
0.60 \\
0.64 \\
0.22 \\
-0.53 \\
-0.51 \\
-0.57\end{array}$ & $\begin{array}{l}2.37 \\
2.77 \\
3.33 \\
3.22 \\
2.33 \\
3.32 \\
3.35 \\
2.12 \\
1.37 \\
2.38 \\
1.49 \\
2.39 \\
2.38 \\
2.29 \\
3.31 \\
3.49 \\
3.33 \\
3.70 \\
4.20 \\
3.30 \\
1.36 \\
2.34 \\
2.38 \\
2.35 \\
2.11 \\
2.19 \\
2.79 \\
2.51 \\
3.10\end{array}$ & $\begin{array}{r}0.088 \\
0.005 \\
-0.018 \\
-0.026 \\
-0.038 \\
-0.012 \\
0.080 \\
0.857 \\
0.036 \\
0.023 \\
0.119 \\
0.027 \\
0.008 \\
0.087 \\
-0.012 \\
-0.020 \\
-0.013 \\
-0.009 \\
-0.000 \\
0.012 \\
0.087 \\
0.043 \\
0.020 \\
0.028 \\
0.029 \\
0.009 \\
-0.014 \\
-0.015 \\
-0.012\end{array}$ \\
\hline
\end{tabular}


is

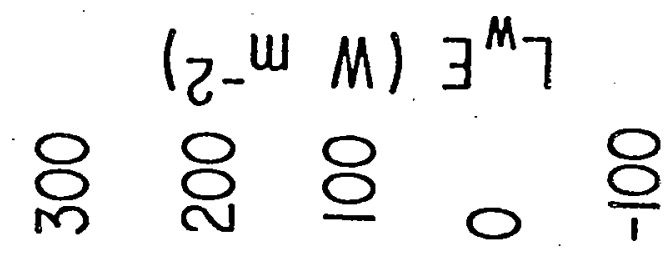

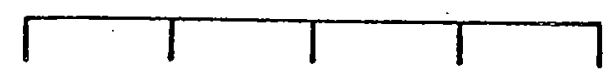
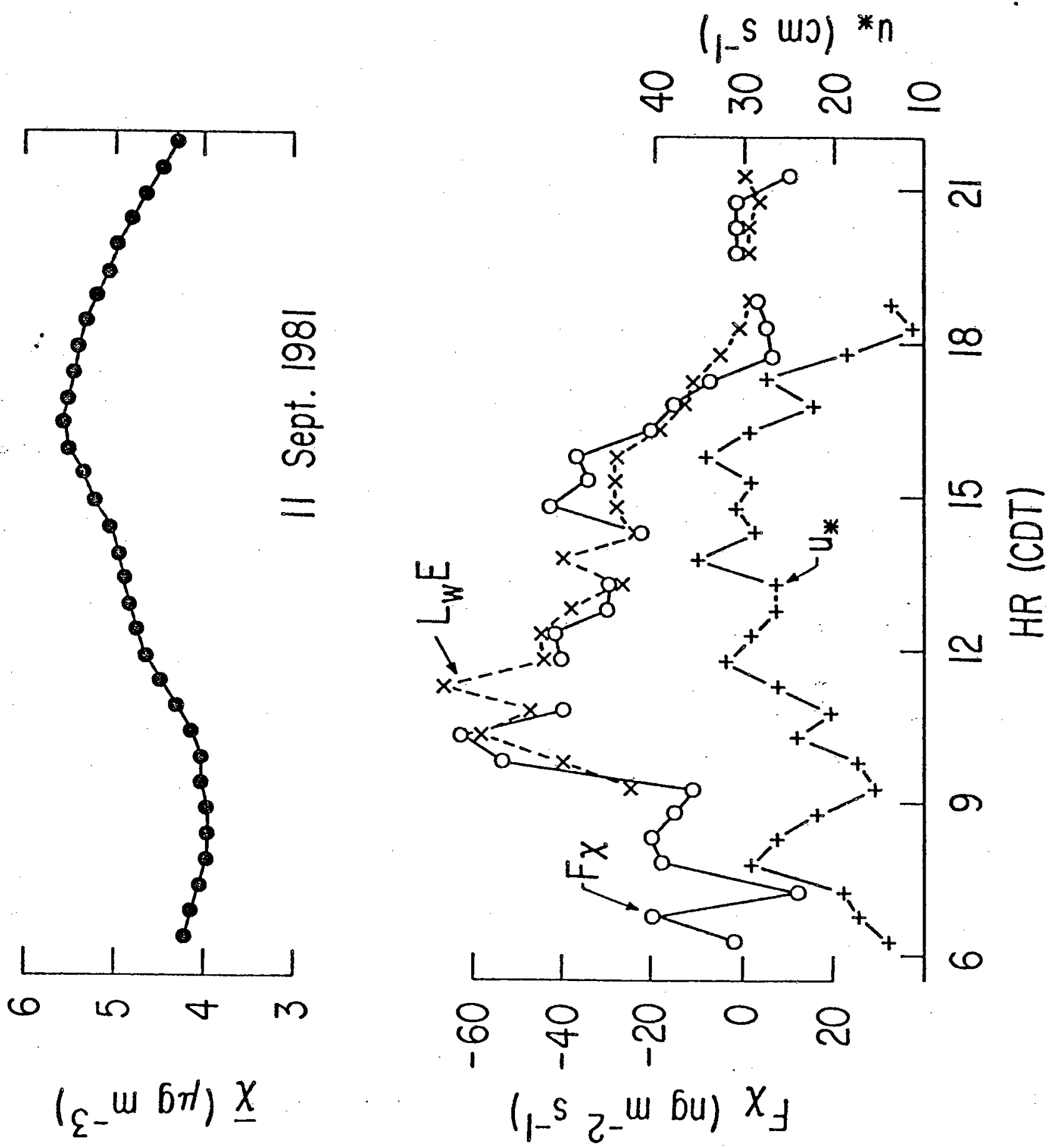

$(\varepsilon-w 6 \pi) \underline{x}$

$$
{ }^{1-2} s^{5-m i n u)} x^{7}
$$


co

is

$$
\begin{aligned}
& \text { (2- } \left.{ }^{m} M\right) \exists^{M} 7 \\
& \text { 융응 운 }
\end{aligned}
$$

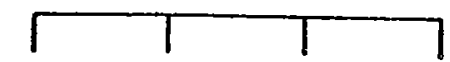

$\bar{\alpha}$
OO
$\dot{0}$
$\stackrel{\circ}{0}$
$m$
m

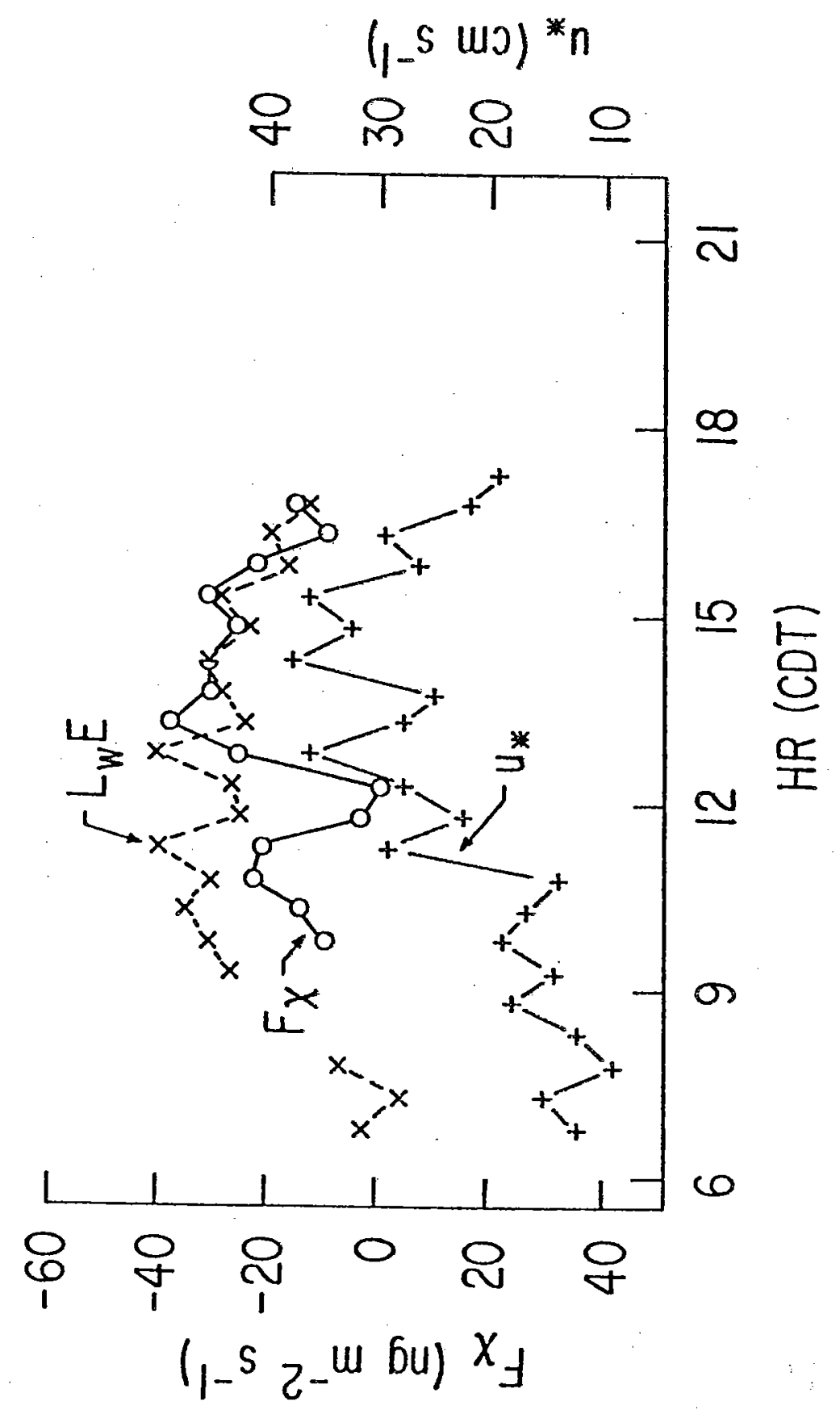


$m$

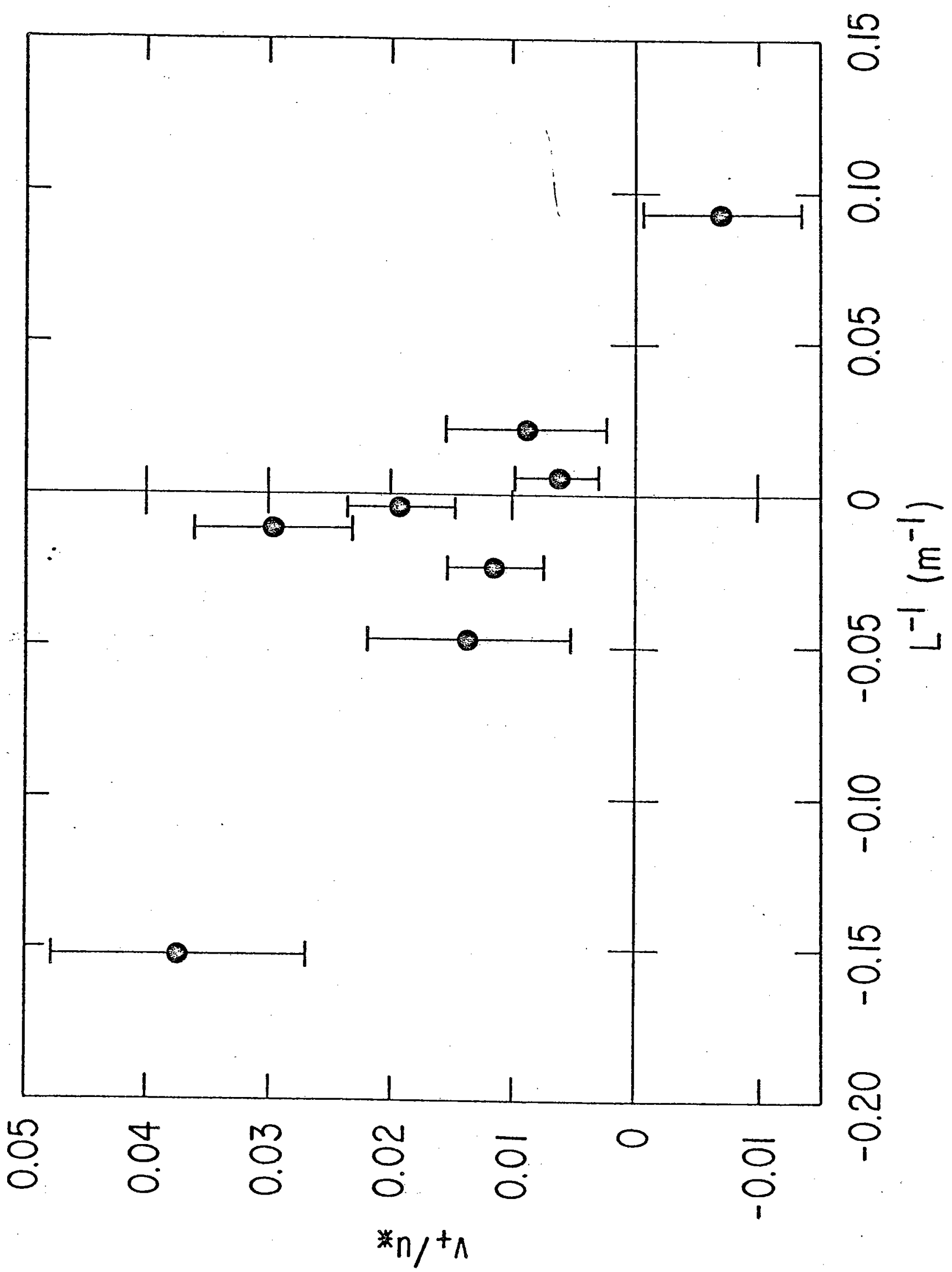



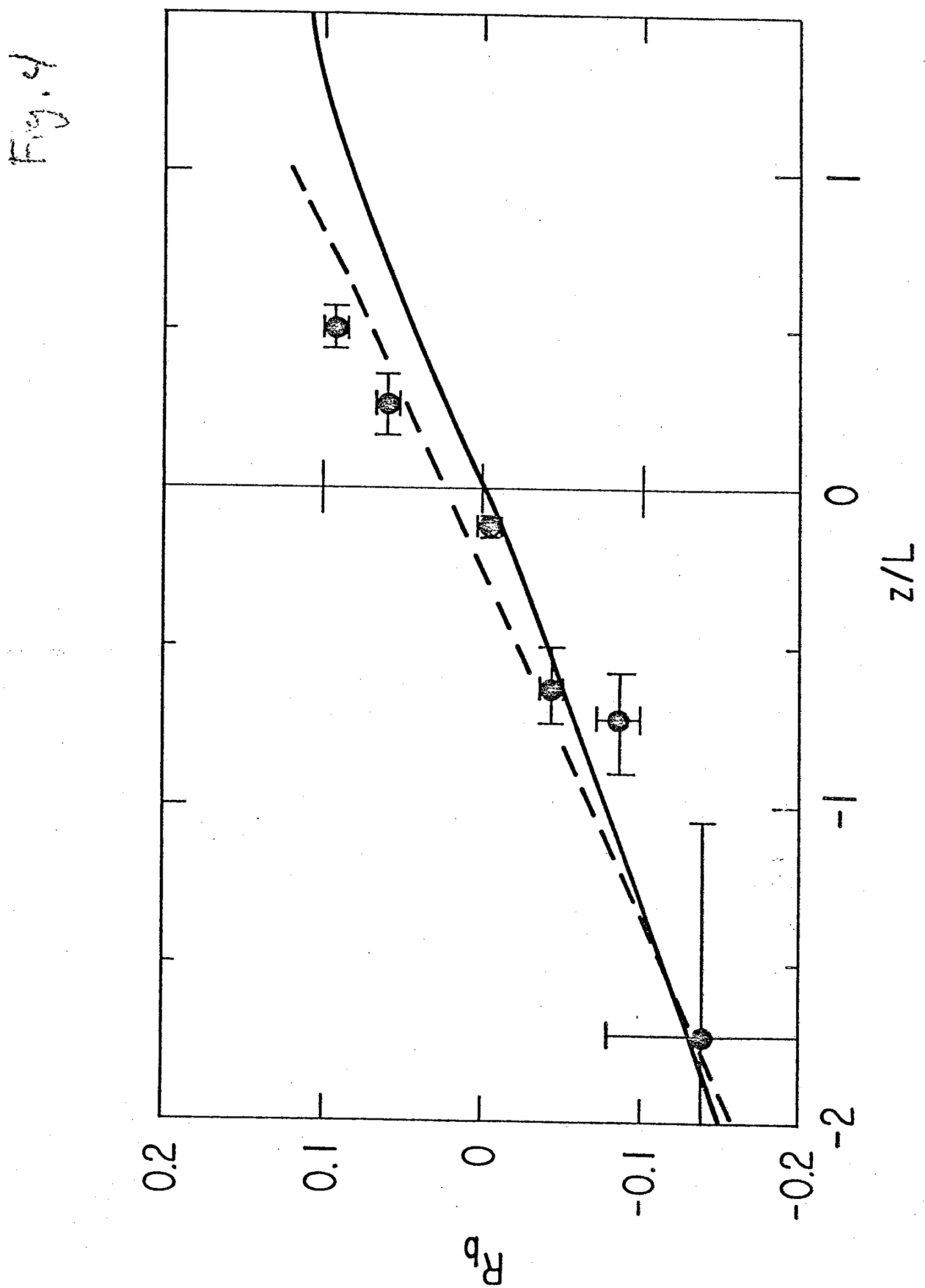